\title{
Incidence of cancer among Swedish military and civil personnel involved in UN missions in the Balkans 1989-99
}

\author{
P Gustavsson, M Talbäck, A Lundin, B Lagercrantz, P-E Gyllestad, L Fornell
}

Occup Environ Med 2004;61:171-173. doi: 10.1136/oem.2002.005538

\begin{abstract}
Leukaemia cases among European UN soldiers in the Balkans have been related hypothetically to exposure to depleted uranium. This study was performed to investigate the risk of cancer among Swedish personnel $(8750$ men and 438 women) involved in UN missions in the Balkans 198999. The overall incidence of cancer was slightly higher than expected; 34 cancers were observed and 28.1 were expected based on national cancer rates. Among military men, there were eight cases of testicular cancer versus 4.6 expected. There was one case of chronic myeloid leukaemia, and no cases of acute leukaemia. The overall risk of cancer was increased in a subgroup of 648 men taking part in convoy operations, based on only five cancers at four different sites. The study gives no support for the hypothesis that UN service in the Balkans could lead to haematolymphatic malignancies after short latency. However, no exposure assessment was performed, and future follow up is necessary for evaluation of long term risks.
\end{abstract}

A mmunition containing depleted uranium was used both during the Gulf War in 1991 and in the Balkan conflict. Seventeen cases of leukaemia among NATO servicemen serving in the Balkans led to great public concern about a cancer hazard from depleted uranium. ${ }^{1}$ Assessments of dose and risk showed that no negative health effects were to be expected, either from the radiological or from the toxicological properties of depleted uranium, and the short latency from the start of exposure was not consistent with a causative role for depleted uranium. ${ }^{2}$ However, no epidemiological studies of cancer incidence among UN personnel serving in the Balkan conflict have been published so far. Other potential cancer hazards have also been present in the environment in the Balkans, such as organic solvents, lubricants, and motor exhaust. This led us to investigate the risk of cancer among Swedish military and civil personnel taking part in UN missions in the Balkans in 1989-99.

\section{METHODS}

The study cohort comprised all Swedish military and rescue services personnel involved in UN missions in the Balkans (Bosnia and Kosovo) from 1989 to 1999. Military personnel were identified from computerised employee registers belonging to the Swedish Armed Forces, and civil personnel were identified from registers belonging to the Swedish Rescue Services Agency. The duration of missions was normally six months. A large number of specific job titles for the military personnel were subdivided into four job groups: (1) work at the camp, mainly indoors; (2) outdoor operations in delimited areas, with transport mainly by foot; (3) outdoor operations over large areas, with transport by convoy; and (4) personnel engaged in mine or ammunition clearance. For each mission, these groups did not overlap, but some persons had served in several missions and may thus have contributed to the observed and expected numbers in several job groups. The civil personnel were employed mainly as vehicle drivers and construction workers. The study was approved by the Ethics Committee of the Karolinska Institutet.

The identification of the cohort and the matching process were based on personal identification numbers. This a 10 digit number unique to every Swedish citizen. Errors in the numbers are uncommon for several reasons, for example, a built-in check number, and repeated cross-checking of employers' payroll registers with those of the taxation authorities, which manage the official (computerised) population registers.

Personal identification numbers from the employee registers were matched to the Swedish cancer register, a national register recording virtually all cancer diagnoses among Swedish residents, as well as to national computerised registers of deaths, emigrations, and the Swedish population at the end of follow up. Follow up could be achieved for $99.9 \%$ of the identified persons, resulting in a final cohort of 8347 military men, 433 military women, 403 civilian men, and five civilian women. The mean age at entry into the cohort was 27.1 (SD 7.0), 33.4 (7.6), 40.0 (9.0), and 37.7 (8.7) for each of these groups, respectively. In all, 30 persons had died and 172 had emigrated during the study period. The rest were verified as living in Sweden at the end of the follow up (31 December 1999).

Person-time under risk was accumulated from the start of the first mission until death, emigration, a diagnosis of cancer, or the end of the study. In all, the cohort accumulated 39816 person-years during the follow up period. Expected numbers of cancers were computed according to the personyear method, based on cancer incidence rates for the general population in Sweden, with adjustment for gender, age (five year classes), and time period (three or four year classes). Standardised incidence ratios (SIR) and exact 95\% confidence intervals (based on the Poisson distribution) were computed.

\section{RESULTS}

There were 34 cases of cancer versus 28.1 expected in the entire cohort, SIR $=1.2(95 \%$ CI 0.9 to 1.7$)$. Male military personnel were the largest subgroup of the cohort. The number of all cancers in this group slightly exceeded the expected number, but not more than what would be expected by chance (see table 1). A breakdown of the analysis by specific cancer sites showed low numbers and no statistically significantly increased SIRs. One finding should be noted, however: there were eight cases of testicular cancer, whereas 4.3 would be expected. Of these eight cases, four were malignant teratomas, three were seminomas, and one was a mixed germinal cell tumour. There were no cases of acute leukaemia, and the total number of haematolymphatic cancers was within expectations. 
Main messages

- Swedish personnel involved in UN missions in the Balkans showed no statistically significantly increased risk of cancer relative to national rates.

- A non-significant excess of testicular cancer deserves future evaluation.

- The period of follow up is presently too short for an assessment of the long term risk of cancer.

There were four cases of cancer among the female military staff, which was slightly more than expected (2.6 cases), but this could have been caused by chance. Among the civilian men, the observed number of all cancers corresponded well with the expected. There were no cancers among the five female civilians in the cohort (not shown in table).

The SIR for cancer was analysed in relation to job group among the male and female military personnel (see table 2 ). Generally, the number of cancers per job group was low, giving wide confidence intervals. The overall SIR for cancer was increased in the convoy group, SIR $=3.0$ (95\% CI 1.0 to 7.0 ), based on only five cancers at four different sites. The excess of testicular cancer that was found in the cohort came from the subgroups outdoors, convoy, and ammunition clearance.

Recently, cancer registrations for the year 2000 became available from the national cancer register. A new matching of the cohort showed no additional cases of testicular cancer for that year.

\section{DISCUSSION}

The total cancer incidence in the entire cohort was within expectations. A breakdown by job group showed an increased SIR for all cancer sites combined in the convoy group, which had presumably been more exposed to motor exhaust than the other groups. However, the types of cancer noted in this subgroup were not among those known to be associated with motor exhaust. ${ }^{3}$ The small excess of testicular cancer that was found in the cohort came from the outdoors, convoy, and
Policy implications

- The study gives no support for the hypothesis that UN service in the Balkans could lead to haematolymphatic malignancies after short latency.

- Future follow up is necessary for assessment of long term risks.

ammunition clearance groups, with a higher potential for contact with depleted uranium than the indoor group. Depleted uranium first came into use in this area in 1994, which was also the year in which the first case of testis cancer was diagnosed. Nevertheless, the latency period from start of employment was short, which does not suggest an aetiological relationship. In general, the Swedish personnel probably had a low degree of contact with depleted uranium. Only one case of testicular cancer occurred in the ammunition clearance group, which had the highest potential for contact with depleted uranium.

Testicular cancer is a common tumour form among young men, and the incidence in the Swedish population is rising. Aetiological factors are largely unknown. ${ }^{4} \mathrm{~A}$ higher relative risk of testicular cancer has been noted among members of the armed forces, although specific mechanisms and explanatory factors are not known. ${ }^{5}$ A cohort study involving 14200 Swedish military men showed a slight excess of nonseminoma testicular cancer ( $\operatorname{SIR}=1.35,95 \%$ CI 0.72 to 2.52 ), and no excess of seminomas. ${ }^{6}$ An increased risk of testicular cancer has been reported in epidemiological studies of workers in occupations involving contact with metals, but the association is not consistently reported..$^{5-9}$ An epidemiological study of 53000 UK Gulf War veterans showed no excess cancer mortality, and no deaths due to testicular cancer. ${ }^{10}$ However, cancer of the testis is often non-lethal and will thus not contribute significantly to death statistics. In all, the small excess of testicular cancer noted in this cohort cannot yet be finally evaluated, but the most likely explanation is chance. A recent re-matching of the cohort to the cancer register showed no cases of testicular cancer for the year 2000.

Table 1 Cancer among Swedish military and civilian personnel in UN missions in the Balkans, 1989-99

\begin{tabular}{|c|c|c|c|c|c|c|c|c|c|c|c|c|c|}
\hline \multirow[b]{3}{*}{ Cancer site } & \multirow[b]{3}{*}{ ICD $-7^{*}$ code } & \multicolumn{8}{|c|}{ Military personnel } & \multirow{2}{*}{\multicolumn{4}{|c|}{$\begin{array}{l}\text { Civil personnel } \\
\text { Men }\end{array}$}} \\
\hline & & \multicolumn{4}{|l|}{ Men } & \multicolumn{4}{|c|}{ Women } & & & & \\
\hline & & Obst & Exp‡ & SIR§ & $95 \% \mathrm{Cl} \mid$ & Obs & Exp & SIR & $95 \% \mathrm{Cl}$ & Obs & Exp & SIR & $95 \% \mathrm{Cl}$ \\
\hline All sites & $140-209$ & 26 & 21.8 & 1.2 & 0.8 to 1.8 & 4 & 2.6 & 1.5 & 0.4 to 3.9 & 4 & 3.8 & 1.1 & 0.3 to 2.7 \\
\hline Oral cavity & $143-144$ & 1 & 0.1 & & & & 0.0 & & & & 0.0 & & \\
\hline Rectum & 154 & 2 & 0.5 & 3.9 & 0.5 to 14 & & 0.0 & & & & 0.2 & & \\
\hline Liver, not specified as primary & $155.1-9$ & & 0.1 & & & & 0.0 & & & 1 & 0.0 & & \\
\hline Bronchus and lung & 162.1 & 1 & 0.8 & & & 1 & 0.1 & & & 1 & 0.3 & & \\
\hline Cervix uteri & 171 & & - & & & 1 & 0.2 & & & & - & & \\
\hline Testis & 178 & 8 & 4.3 & 1.9 & 0.8 to 3.7 & & - & & & & 0.2 & & \\
\hline Urinary bladder & 181.0 & 2 & 0.7 & 2.9 & 0.4 to 11 & & 0.0 & & & & 0.2 & & \\
\hline Malignant melanoma & 190 & 2 & 2.2 & 0.9 & 0.1 to 3.3 & 1 & 0.3 & & & 1 & 0.3 & & \\
\hline Brain and nervous system & 193 & 3 & 2.6 & 1.2 & 0.2 to 3.4 & 1 & 0.2 & & & 1 & 0.3 & & \\
\hline Endocrine glands & 195 & 1 & 0.7 & & & & 0.1 & & & & 0.1 & & \\
\hline Unknown site & 199 & 1 & 0.6 & & & & 0.0 & & & & 0.1 & & \\
\hline Haematolymphatic organs & 200-209 & 5 & 3.5 & 1.4 & 0.5 to 3.3 & & 0.2 & & & & 0.5 & & \\
\hline Non-Hodgkin's lymphoma & 200 & 1 & 1.2 & & & & 0.1 & & & & 0.2 & & \\
\hline Hodgkin's disease & 201 & 2 & 1.1 & 1.9 & 0.2 to 6.7 & & 0.0 & & & & 0.0 & & \\
\hline Myelomatosis & 203 & 1 & 0.2 & & & & 0.0 & & & & 0.1 & & \\
\hline Chronic myeloid leukaemia & 205.1 & 1 & 0.3 & & & & 0.0 & & & & 0.0 & & \\
\hline
\end{tabular}

*International classification of diseases, 7th revision.

†Observed number of cases.

†Expected number of cases.

$\S$ Standardised incidence ratio, not calculated if there were less than two cases.

$95 \%$ confidence interval. 
Table 2 Cancer among Swedish military personnel (men and women) in UN missions in the Balkans, 1989-99, subdivided by job group*

\begin{tabular}{|c|c|c|c|c|c|c|c|c|c|c|c|c|c|c|c|c|}
\hline \multirow[b]{2}{*}{ Cancer site $†$} & \multicolumn{4}{|c|}{ Indoors, $n=3412$} & \multicolumn{4}{|c|}{ Outdoors, $n=5204$} & \multicolumn{4}{|c|}{ Convoy, $n=648$} & \multicolumn{4}{|c|}{ Ammunition clearance, $n=357$} \\
\hline & Obs & Exp & SIR & $95 \% \mathrm{Cl}$ & Obs & Exp & SIR & $95 \% \mathrm{Cl}$ & Obs & Exp & SIR & $95 \% \mathrm{Cl}$ & Obs & Exp & SIR & $95 \% \mathrm{Cl}$ \\
\hline All sites $\ddagger$ & 15 & 11.3 & 1.3 & 0.7 to 2.2 & 14 & 12.4 & 1.1 & 0.6 to 1.9 & 5 & 1.7 & 3.0 & 1.0 to 7.0 & 1 & 0.4 & & \\
\hline Rectum & & 0.3 & & & 2 & 0.2 & 8.1 & 1.0 to 29 & & 0.0 & & & & 0.0 & & \\
\hline Bronchus and lung & 1 & 0.5 & & & 1 & 0.4 & & & & 0.1 & & & & 0.0 & & \\
\hline Testis§ & 1 & 1.5 & & & 6 & 2.7 & 2.2 & 0.8 to 4.9 & 2 & 0.3 & 5.9 & 0.7 to 21 & 1 & 0.1 & & \\
\hline Urinary bladder & 1 & 0.4 & & & 1 & 0.3 & & & & 0.0 & & & & 0.0 & & \\
\hline Malignant melanoma & 2 & 1.1 & 1.8 & 0.2 to 6.5 & 1 & 1.3 & & & 1 & 0.2 & & & & 0.0 & & \\
\hline Brain and nervous system & 3 & 1.1 & 2.7 & 0.6 to 7.8 & 31 & 1.5 & & & & 0.2 & & & & 0.1 & & \\
\hline Haematolymphatic organs & 3 & 1.5 & 2.0 & 0.4 to 5.8 & 1 & 2.0 & & & 1 & 0.3 & & & & 0.1 & & \\
\hline Hodgkin's disease & 1 & 0.4 & & & 1 & 0.7 & & & & 0.1 & & & & 0.0 & & \\
\hline
\end{tabular}

*The table lists observed and expected cancers since service in the respective group started. Some persons had worked in two or more groups in different missions, and the numbers cannot be added over job groups.

tOnly sites with at least two cases are shown.

$\ddagger$ Three persons with cancer had served in two or more job groups.

$\S$ One person with testicular cancer had served in three job groups.

-One person with malignant melanoma had served in three job groups.

The study did not confirm an increased risk of haematolymphatic malignancies, which was the original observation prompting the study. ${ }^{1}$ If depleted uranium causes cancer in humans, lung and bone would be the primary target organs. ${ }^{11}$ No excess of lung cancer was noted in this cohort, and there was no case of bone cancer.

So far, this cohort shows no indications of a statistically significantly increased incidence of cancer, but the period of follow up is too short for an assessment of the long term risk of cancer. No assessment of the individual exposure to depleted uranium or other work related exposures could be performed, and the study would be expected only to detect hazards from exposures that are common within one or more of the studied job subgroups, unless excess risks are very high. The cohort will be the subject of future follow up.

\section{ACKNOWLEDGEMENTS}

We thank M Lundström and P Wallström at the Swedish Armed Forces, and B Åhlén at the Swedish Rescue Services Agency for assistance in data collection. The study was funded by the Swedish Armed Forces.

\section{Authors' affiliations}

P Gustavsson, A Lundin, Dept of Occupational and Environmental Health, Stockholm Center for Public Health, Stockholm, Sweden M Talbäck, Centre for Epidemiology, National Board of Health and Welfare, Stockholm, Sweden

B Lagercrantz, Headquarters, Swedish Armed Forces, Stockholm, Sweden
P-E Gyllestad, SWEDINT, Swedish Armed Forces, Stockholm, Sweden L Fornell, Swedish Rescue Services Agency, Karlstad, Sweden

Correspondence to: Dr P Gustarsson, Dept of Occupational and Environmental Health, Karolinska Hospital, SE-171 76, Stockholm, Sweden; per.gustavsson@smd.sll.se

Accepted 17 April 2003

\section{REFERENCES}

1 Anon. Mixed messages about depleted uranium [editorial]. Lancet Oncol 2001;2(2):65.

2 Priest ND. Toxicity of depleted uranium. Lancet 2001;357:244-6.

3 Boffetta P, Jourenkova N, Gustavsson P. Cancer risk from occupational and environmental exposure to polycyclic aromatic hydrocarbons. Cancer Causes Control 1997;8:444-72.

4 Adami HO, Bergstrom R, Mohner M, et al. Testicular cancer in nine northern European countries. Int J Cancer 1994:59:33-8.

5 Schottenfeld D. Testicular cancer. In: Schottenfeld D, Fraumeni JF, eds. Cancer epidemiology and prevention, 2nd edn. Oxford: Oxford University Press, 1996:1207-19.

6 Pollán M, Gustavsson P, Cano MI. Incidence of testicular cancer and occupation among Swedish men gainfully employed in 1970. Ann Epidemiol 2001; 11:554-62.

7 Hansen KS, Lauritsen JM, Skytthe A. Cancer incidence among mild steel and stainless steel welders and other metal workers. Am J Ind Med 1996:30:373-82.

8 Rhomberg W, Schmoll HJ, Schneider B. High frequency of metalworkers among patients with seminomatous tumors of the testis: a case-control study. Am J Ind Med 1995;28:79-87.

9 Van den Eeden SK, Weiss NS, Strader CH, et al. Occupation and the occurrence of testicular cancer. Am J Ind Med 1991;19:327-37.

10 Mould RF. Depleted uranium and radiation-induced lung cancer and leukaemia. Br J Radiol $2001 ; 74: 677-83$.

11 Schiermeier Q. Scepticism greets claims that uranium shells cause leukaemia. Nature 2001;409:121. 